\title{
Una política financiera a medias
}

Rafael Rodríguez Loucel

Asesor de la Presidencia

y miembro del Senado Consultivo de la UTEC

\section{INTRODUCCIÓN}

$\mathbf{P}$ or política financiera, en este artículo, deberá entenderse la que el Gobierno aplica; y es un tema que se ha creído oportuno incluirlo en la revista Entorno de la Universidad Tecnológica de El Salvador, en razón de la situación económica prevaleciente caracterizada por sus déficit permanentes en prácticamente todas los ángulos del quehacer económico del país (corrientes reales y corrientes financieras), y los cuales se han magnificado en los últimos años en gran parte por la crisis financiera mundial. Pero, por otra parte, por el manejo inadecuado de la política macroeconómica y la prioridad del interés privado sobre el colectivo. El Salvador se ha caracterizado por sus limitaciones de origen y adquiridas en su desenvolvimiento como país, carencias que, exacerbadas, han propiciado una crisis integral al suscitarse desequilibrios también pronunciados: en lo social, político, cultural y ambiental. Este ensayo no pretende incursionar en un diagnóstico en estos últimos aspectos, solo pretende señalar los inconvenientes de una política financiera incompleta.

\section{POLÍTICA FINANCIERA}

Una política financiera de un gobierno, al menos en teoría, implica la aplicación conjunta de la política monetaria y la política fiscal operando en forma conjunta y coordenada. Una política financiera (política fiscal y política monetaria) tiene un área amplia de acción, y podría afirmarse que persigue al menos los siguientes objetivos: afectar los niveles de ingreso y el producto (política anticíclica), regular los niveles de precio e incidir en el balance de pagos. La política mencionada es de corto plazo y trata, en la medida de lo posible, de lograr la plena capacidad de la economía, evitando procesos inflacionarios. En una situación como la que caracteriza al país -en franco deterioro-, una política financiera podría orientarse a remover al sistema económico de su entorpecimiento, o "entrampamiento", como lo denomina Alberto Arene -conocido economista de este país-, sin modificar las condiciones básicas de la oferta y la demanda; aspectos que son del ámbito de la política global de desarrollo, la cual pretende incrementar la oferta por medio de la ampliación de las existencias, la mejora del nivel de tecnología, el incremento de la productividad e influir en la demanda por medio de estímulos a la inversión privada y pública.

En el caso de El Salvador, fue hasta Enero de 2001 que se declaró el país oficialmente dolarizado al entrar en vigencia la Ley de Integración Monetaria, con lo cual el Banco Central de Reserva (BCR) dejó de ser el prestamista de última instancia, y la política monetaria, prácticamente desapareció como componente de la macro- política económica o de lo que aquí —en este ensayo- hemos denominado política financiera. La decisión tuvo argumentos técnicos de parte de los encargados del hacer gubernamental y tomadores de decisiones de esa época, pero también existió una dosis importante de política en el sentido aislado de la palabra e intereses de índole particular; pero no es el objetivo de este trabajo el cuestionar esos móviles. Se trata únicamente de puntualizar las implicaciones que ha tenido esa decisión para el país como un todo. 


\section{POLÍTICA MONETARIA}

Recordando el pasado, y a manera simplemente de orientación o de ilustración, podemos echar mano de algunos conceptos de lo que podría entenderse como política monetaria. Política monetaria es aquella disciplina que influye sobre la actividad económica a través de instrumentos como son: la variación del tipo de redescuento, el encaje legal, las operaciones de mercado abierto, la asignación crediticia por sectores productivos auxiliándose de los intermediarios financieros privados y autónomos de carácter público. En el juego de la política monetaria de lo que se trata es de ajustar la cantidad de un bien singular, como es el dinero; y de un precio muy especial, como es la tasa de interés. La política monetaria se ve influenciada y complementada por la política cambiaria y por la política crediticia. Tratando de ser más preciso, en el marco de las políticas que las autoridades monetarias tenían a disposición antes del 2001 existe una ecuación singular que es aquella en que la oferta monetaria es igual a los activos internacionales netos más o menos los activos internos netos (O M = RIN + _ AIN). Como puede apreciarse, existía una relación de causa efecto, o sea, una íntima relación entre las tres políticas.1/

Dentro de un sistema de tasas de cambio como el que existía en el país, se presentaba una situación en la que la oferta monetaria estaba influenciaba por razones exógenas y razones endógenas. Razones exógenas son aquellas determinadas por los resultados de la balanza de pagos; si se presenta un déficit de la balanza de pagos, o sea, una disminución de las reservas internacionales netas se ejerce un efecto contractivo en la oferta monetaria, esto es, en los medios de pago. En caso contrario, sucede el efecto inverso. El problema se presenta con los resultados de balanzas de pagos que están influidas por los resultados de la cuenta corriente y de la cuenta de capital; la primera de ellas, básicamente determinada por la diferencia entre las exportaciones e importaciones de bienes y servicios; y la segunda, por el resultado neto de los flujos de capital del exterior. Como puede apreciarse, tales resultados escapaban al manejo o acción de las autoridades monetarias de entonces.2/

En lo que respecta al crédito, el Banco Central podía controlar sus niveles a fin de mantener un nivel de precios y volumen de producción y empleo. Dicho control se podía realizar mediante la tasa y diferenciales de redescuento, operaciones de mercado abierto, el encaje legal de los bancos comerciales, coeficientes de liquidez y los controles directos selectivos del crédito. Se deduce que el crédito era una variable endógena que era, hasta cierto punto, manipulada por las autoridades monetarias para incidir en la oferta monetaria, operaba en el mismo sentido que las reservas internacionales; es decir, si aumentaba el crédito había una expansión en la oferta monetaria; en caso contrario, el efecto era inverso. De lo expresado anteriormente puede colegirse que los instrumentos que controlaban el crédito se volvían mecanismos de control de la oferta monetaria o de los medios de pago.3/

En la ley orgánica del BCR se establecía que el objetivo fundamental de la política monetaria era la estabilidad monetaria, el cual podía medirse anualmente a través de los incrementos generalizados de precios de la economía, constituyéndose esa estabilidad en el mayor aporte del banco. Para ello existían asideros legales, entre otros: la Constitución de La República de El Salvador en su título V. "Orden Económico", Artículo 111, párrafo segundo establece: “El Estado deberá orientar la política monetaria con el fin de promover y mantener las condiciones más favorables para el desarrollo ordenado de la economía nacional". Por su parte, el Artículo 3 de la Ley Orgánica del BCR, determinaba que dicha institución "tendrá por objeto fundamental velar por la estabilidad de la moneda, y será su finalidad 
esencial promover y mantener las condiciones monetarias, cambiarias, crediticias y financieras más favorables para la estabilidad de la economía nacional".

"Para ejercitar sus atribuciones la ley del BCR, asignaba funciones específicas como la de emitir moneda, prevenir o moderar tendencias inflacionarias, mantener la liquidez y estabilidad del Sistema Financiero, fomentar su desarrollo, regular la expansión del crédito, velar por el normal funcionamiento de los pagos internos y externos, adecuar los medios de pago al desarrollo de las actividades productivas, administrar las reservas internacionales, dictar normas correspondientes en materia monetaria, crediticia, cambiaria y financiera, coordinar sus políticas con la política económica del gobierno. Dicha ley definía al Banco Central como una institución de carácter autónomo, asignándole además facultades administrativas, técnicas y financieras con el propósito de conducir la política monetaria con un criterio técnico, libre de presiones institucionales o sectoriales, que facilitarán la consecución del objetivo de mantener la estabilidad monetaria dentro de sus limitaciones."4/

Como puede deducirse de lo anteriormente expuesto, la política monetaria era un elemento trascendental y estratégico en la conducción de una política macroeconómica estable. Para los efectos de este trabajo, deberá entenderse también las áreas cambiaria y crediticia; todas las cuales, actuando en forma conjunta, conformaban y propiciaban la estabilidad financiera que coadyuvaba a una estabilidad macroeconómica, si se acompañaba de una política fiscal moderada.

\section{POLÍTICA FISCAL}

Se entiende por política fiscal el conjunto de medidas relativas al régimen tributario, gasto público, endeudamiento interno y externo del Estado, y las operaciones y situación financiera de las entidades y organismos autónomos o paraestatales, y por medio de los cuales se determina monto y distribución de la inversión y consumo públicos, como componente del gasto nacional.5/ .Esta definición, de Méndez Morales, se interpreta apegada a la operatividad de la actividad presupuestal del gobierno; pero como política, en el sentido estricto, se quiere poner de relieve la connotación de que existe una función implícita y de fondo en una política fiscal; y es su acción redistribuidora del ingreso como captador de impuestos traducidos posteriormente en gasto social. Por tal razón, conviene retornar a Méndez Morales cuando expresa: "Depende de lo que se considere en cada país debe ser la función social del Estado. En la medida que se acepte que el sector público absorbe ingresos privados por medio de impuestos, Ios traslada a otras manos, crea inversiones y gastos"6/

A propósito de la función redistribución del ingreso del gobierno, identificada con la acción paralela de recaudar el dinero de unos y asignárselos a otros, es una cuestión bastante controversial. El criterio no es el simple hecho de extraer riqueza e ingresos del rico para dárselos al pobre; el principio tiene que ver con la utilización/beneficio de los bienes del Estado, y parte de la convicción de una honradez y ética de los encargados, haciendo de lado el interés particular de los funcionarios públicos. Se basa exclusivamente en el principio de equidad de la política fiscal, aplicable a los países que desean una asignación justa y una utilización racional de los recursos en función de un desarrollo sostenible. Un ejemplo. Si se trata de crear el ahorro público suficiente para hacer frente al volumen de inversiones y absorber de la economía privada recursos para la provisión de servicios públicos, la reasignación es necesaria. En países hoy en día desarrollados, la carga impositiva (tributación/producto interno bruto) es alta, pero el gasto público se asigna a 
gastos que se identifican con servicios públicos plenamente asociados como impulsores del crecimiento y generadores de calidad de vida generalizada (salud y educación gratuita de calidad, entre otros).

\section{CÓMO OPERA UNA POLÍTICA FINANCIERA}

“En el corto y mediano plazo, las autoridades económicas tienen cuatro objetivos simultáneos: reducir o mantener el desempleo en un nivel bajo, asegurando un crecimiento sostenido, controlando la inflación y vigilando los desequilibrios potenciales que pueden surgir: fiscales o externos. El arte de la política económica es el tornar compatibles las esquinas de este cuadrado mágico".7/ Retomaremos este cuadrado mágico como herramienta de análisis de la situación actual prevaleciente en el país.

Antes de intentar un examen de la situación particular del país, es conveniente repasar unos conceptos de política fiscal aplicables a la política financiera como se ha concebido en estos breves comentarios:

La política fiscal y/o política monetaria puede ser expansiva (inflación alta, a veces) o restrictiva (contraccionista). La primera persigue aumentar la demanda, y la segunda reducirla con el aumento o disminución del dinero en circulación con los instrumentos de que se dispone: impuestos, gasto, dinero en circulación, crédito, (tasas, consumo, inversión, redescuento, encaje, etc.). Lógicamente, para que estos instrumentos operen tendrán que estar disponibles y también existir situaciones extremas de expansión y recesión.

\section{CRISIS FINANCIERA}

"La actual crisis resulta de la coincidencia de unos reducidos tipos de interés en los primeros años de este siglo y el movimiento desregulatorio que comenzó en la década de 1970. Las crisis financieras vividas en los últimos años: la quiebra del fondo Long Term Capital Management (LTCM) en 1998, la crisis de la nueva economía en 2000, los atentados del 11 de septiembre de 2001, se han solventado aplicando una relajación monetaria mediante reducciones drásticas en Ios tipos de interés. Estos han podido mantenerse a un nivel reducido gracias al éxito de unas políticas monetarias que han mantenido la tasa de inflación en niveles históricamente bajos en las principales zonas económicas desarrolladas. Tipos de interés reducidos hacen que el endeudamiento sea barato, a la vez que la remuneración de tipos de ahorro seguro, como los certificados de depósito, depósitos bancarios, bonos del tesoro, disminuye. Como consecuencia, el endeudamiento aumenta y el ahorro disminuye."8/.

Una cita tan extensa tiene su justificación para explicar la utilización de la política monetaria (ventajas y desventajas) con un grado de desarrollo importante o en situaciones de expansión o contracción relativa, como la que existió en el siglo pasado y en los últimos años. En El Salvador se registra un caso singular: una economía pequeña, de baja productividad, presentando situaciones de crecimiento promedio anual bajo, movimientos inflacionarios de índole exógena y endógena y con una política financiera a medias.

La política financiera, como puede percibirse, resulta compleja; si las circunstancias son normales, es aceptable que la mejor manera de condicionarla es tomando las medidas que mantengan el equilibrio del producto a nivel de plena capacidad, corrigiendo con la prontitud debida cualquier proceso expansionista, o bien contractivo, que se suscite en forma eventual. Sin embargo, existen circunstancias en que se hace necesario acelerar el crecimiento, permitiendo políticas expansionistas sin que se pueda evitar la inflación; en este caso pueden adoptarse medidas de orden correctivo, que generalmente son adoptadas en forma aislada (de 
orden microeconómico); y tienen la desventaja de que crean distorsiones del mercado de oferta y demanda, corrupciones e injusticias. Entre tales medidas pueden citarse los controles de precios, racionamiento, subsidios, restricciones comerciales, etc.

Y "aunque usted no lo crea", hoy en día —en el caso específico de El Salvador, y todo dentro de lo relativo- las autoridades afrontaron dilemas con la búsqueda de dos tipos de equilibrio, que en el pasado no eran coincidentes, eran más bien antagónicos: el equilibrio interno versus el equilibrio externo. A manera de ejemplo: si deseaba crecimiento, algunas veces se estimulaba la inflación; si se deseaba crecimiento, algunas ocasiones se generaban déficit fiscales; si se deseaban desajustes en la balanza de pagos, se estimulaba la demanda. Ahora bien, el proceso contrario: si quería evitar la inflación, los déficit fiscales y equilibrar la balanza de pagos, se contraía la demanda, sacrificando el crecimiento económico. La política financiera también tenía que afrontar el hecho contradictorio que lo que es beneficioso desde el punto de vista técnico-económico no era atractivo desde el punto de vista político; una política expansionista, lógicamente, era más atractiva y popular, pero en determinadas circunstancias nos conducía a un desequilibrio interno y externo, reflejándose en déficit de balanza de pagos, déficit presupuestario y altas tasas de inflación.

\section{EI SALVADOR DE HOY (CONCLUSIONES)}

Hoy en día todo lo anterior parece "ciencia ficción". Para empezar, no hay políticas monetaria, cambiaria y crediticia. "Todo es circunstancial y solucionable." Se tiene que vivir con desajustes de toda índole (estancamiento e inflación real), dolarización, con pocas reservas monetarias (las que posee el BCR), alta deuda externa, déficit fiscal significativo, altas tasas de desempleo real y disfrazado, salarios reales bajos, contracción de la demanda externa, mayor dependencia externa, remesas familiares como flujo importante de ingreso de divisas y contracción económica. La búsqueda constante de ese cuadrado mágico, esta vez en todas sus esquinas: empleo, equilibrio externo, equilibrio fiscal y control de la inflación, es díficil. Con la crisis interna, y la influencia de la crisis externa, la dificultad es aún mayor y su solución se torna algo casi imposible. La problemática se amplía, se ha vuelto una multicrisis e incluye los campos social, político, ambiental, y, por lo tanto, es algo más que estructural, se identifica más acertadamente como "un fenómeno de orden cultural".

La política monetaria y sus derivados, dejaron de existir desde el momento en que apareció la dolarización en forma oficial, al adoptarse esta moneda extranjera (el dólar) como de curso legal desde el 1 de enero de 2001, con la entrada en vigencia de la ley que planteaba un bimonetarismo, que fue más bien enunciativo porque, de acuerdo con un artículo de dicha ley, el BCR debía de recolectar los colones disponibles; y esta institución perdió su función de emisor y prestamista de última instancia. Después de diez años de dolarización, sus objetivos de orden financiero son cuestionables, $y$, además, existe una caída de la inversión extranjera, de la productividad y un sector exportador diezmado.

Los problemas del país trascienden los objetivos que se pretendían alcanzar con la dolarización. Según autores como Jeffrey Sachs y Felipe Larrrain, este cambio monetario es más considerado una "camisa de fuerza" antes que una salida viable para las economías latinoamericanas. La imposibilidad de devaluar la moneda para incentivar las exportaciones, la dependencia de los Estados Unidos y la necesidad de mantener un balance presupuestario son elementos que preocupan a los economistas." 
En el caso específico de El Salvador, en la decisión de tomar la medida de dolarizar la economía, existieron o debió haber habido razones técnicas, políticas y circunstanciales. Se dice "debió" por que fueron inconsultas, a pesar de que cambiar la moneda de un país se asemeja a cambiar un símbolo, e idealmente pudo haberse dado una consulta popular al afectar los presupuestos de todos los ciudadanos en una proporción relativa, "pero a todos". Cronológicamente se convirtió, en forma deliberada o casual, en antesala de la venta de los bancos comerciales a inversionistas extranjeros. Pero no se trata de especular ni de emitir juicios de valor en este artículo, sino de subrayar el hecho de que la política financiera opera a medias y ya no cuenta con la política monetaria para compensar o contrarrestar las acciones derivadas de la política fiscal; tampoco para contrarrestar un período de estancamiento de la economía. El desenvolvimiento de una política financiera sin política monetaria se ha realizado, hasta la fecha, en un período de desaceleración económica marcada, después de un periodo de reactivación relativa (efecto rebote efímero por el desborde del consumo duradero característico de una postguerra doméstica); de una dependencia en las transferencias del exterior (remesas familiares) más marcada en la cuenta corriente de la balanza de pagos; de un endeudamiento público extraordinario; de una venta de la banca comercial a inversionistas extranjeros; de llegar hasta un decrecimiento del producto, mayor desempleo provocado por la crisis internacional y nacional de la economía, dificultades de obtención de crédito por insolvencia y ausencia de proyectos. Los mecanismos financieros tradicionales de expansión (Ios identificados con la política fiscal), por lo tanto, no han podido operar con la celeridad del caso y en un contexto normal.

\section{REFLEXIONES FINALES}

A todos estosúltimos hechos, que son de orden estrictamente económico, se agregan los fenómenos asociados con la violencia, la delincuencia, la pobreza extrema, el desempleo, la partidocracia, la vulnerabilidad del territorio a fenómenos naturales (el invierno), el incremento en la canasta básica y las anomalías institucionales; todos, han agravado la situación del país. Ayer se denominaban estructurales; y hoy, por su continuidad y magnitud se les identifica como culturales. La crisis resulta de tal magnitud que el cuadrado mágico - del que hablamos en determinado momento- pierde su sentido al perder las metas y objetivos; y "el timón" gira descontroladamente; y la forma de afrontar los dilemas de un sistema económico arriesgan el presente y el futuro. No es posible reducir el papel de las políticas macroeconómicas a mantener los equilibrios, en tanto y en cuanto lo que se hace y lo que se deja de hacer tiene efectos significativos sobre la evolución de las economías.

La política fiscal, esa parte que se refiere al manejo de los ingresos, gastos y deuda pública y hace abstracción de las prácticas redistributivas, es la que opera en la actualidad, fincando su atención en los malabarismos presupuestarios, con una carga tributaria de alrededor del $13 \%$, que no es consecuente con un país que se supone aspira a un mayor crecimiento con equidad y como corolario a un mayor nivel de vida generalizado; los impuestos. que pudieran incrementar la carga tributaria, deberán ser preferentemente directos, a manera de iniciar esa función por excelencia de redistribuir el ingreso de los que tienen mayor capacidad de tributación hacia aquellos que viven en condiciones de extrema pobreza; pero la concepción básica es de crear oportunidades de trabajo a través de una mayor inversión pública ejecutada con extrema transparencia y en el marco de austeridad palpable en el gasto corriente. 
La credibilidad de los ciudadanos en las autoridades es fundamental para asimilar y cumplir los preceptos y leyes dictados por el gobierno de turno. Caso contrario, el rechazo y la evasión es la respuesta colectiva. La lógica está basada en el comportamiento humano promedio. Ese $13 \%$ tributario habrá que incrementarlo con un esquema impositivo adicional que efectivamente sea distributivo, y que esos ingresos adicionales sean para fines específicos, ligados al desarrollo sostenible, descartando el interés y el enriquecimiento privado. El impuesto que se asegura servirá para gastos de seguridad, basado en el valor de la propiedad, que por su fuente de captación se asemeja a un impuesto territorial o predial, en otras circunstancias, podría haber sido para educación, consciente en extremo que el mayor gasto orientado a ese rubro es la clave del desarrollo. Este tipo de impuestos directos con destino específico, administrados en forma transparente, podrían contribuir a elevar selectivamente esa carga tributaria, si con ello se eleva la calidad de vida de la gran mayoría.

Una revisión concienzuda de la orientación del gasto es necesaria. La política de subsidios requiere una revisión a fin de asegurar su adecuada orientación. Una sugerencia es que se debían de orientar a satisfacer la producción en búsqueda de la soñada competitividad, en lugar sostener el consumo. Nunca será repetitivo sugerir que, en el gasto, la educación y la investigación en ciencia y tecnología tenga una mayor preferencia, incrementando estas erogaciones en un porcentaje mayor que el actual en relación con el PIB.

Un pacto fiscal debería iniciarse por definir en forma consensuada con los contribuyentes el mínimo de gasto corriente y de inversión gubernamental, para una operatividad normal del mismo gobierno, y el financiamiento de un mínimo de proyectos necesarios para hacer efectivo un desarrollo sustentable; prioridad que deberá ser diseñada con criterios técnicos en un esquema de concertación.

Se debería de estudiar las posibilidades de mecanismos que operen a semejanza del encaje y el redescuento de antaño, diseñados por el BCR y aplicados por la Superintendencia ya consolidada, en vista del alto grado de liquidez de la actual banca comercial extranjera operando en el territorio, fondos que podían servir para financiar proyectos estratégicos para un desarrollo sustentable.

\section{Referencias}

1) Rafael Rodríguez Loucel, “50 años de Política Monetaria en El Salvador" (Conferencias conmemorativas Quincuagésimo Aniversario).

2) Idem

3) Idem

4) Tomás Ricardo López, “Elementos de la Política Monetaria en El Salvador hasta el año 2000."

5) José Silvestre, Méndez Morales. Problemas Económicos de México Ed. McGraw Hill.

6) Idem

7) Ricardo Martner, experto de la Dirección de Programación del Sector Público del Instituto Latinoamericano y del Caribe de Planificación Económica y Social (ILPES/CEPAL).

8) Alfonso Novales. "Política Monetaria antes y después de la crisis financiera," Departamento de Economía Cuantitativa Universidad Complutense. 